\title{
The Power of Bromance in BL Fiction: A Homosexual Narrative in Chai Jidan's Addicted
}

\author{
Wenhsiang Su Ph.D. \\ Assistant Professor, Dept. of Applied English \\ Shih Chien University Kaohsiung Campus, \\ NO. 200 University Rd. Neimen Dist. Kaohsiung Taiwan
}

\begin{abstract}
Male friendship has been an intriguing topic since ancient times. The relationship between two men with emotionally intense bonding or special intimacy has long been considered brotherhood. In respect of modern terminology, such friendship can be termed bromance. In human history, bromance used to be praised and documented in literature. Numerous examples can be found in both the West and the East. As time went by, bromance came to be regarded as an act of committing homosexuality. In this paper, I would like to discuss two major protagonists, Bai Luo Yin (Yin Zi) and Gu Hai, in Addicted by a Chinese female writer, Chai Jidan. This novel, also adopted for a TV drama, aroused dispute in China because of its controversial topic. As slash fiction, or so called Boys Love (BL), Addicted has triggered the issue of homosexuality since its first release. Though banned from airing on TV, the audience's awareness of homosexuality awoke because of the admiration of the fearless love between these two protagonists. In this regard, this paper will begin with an analysis of sexuality, and then will further explain why BL, with a homosexual narrative, attracts readers and viewers despite its polemical controversy.
\end{abstract}

Keywords: brotherhood, bromance, Addicted, sexuality, homosexuality, Boys Love, slash fiction

Homosexuality used to be a taboo and was considered a transgression that violated morality and ethics. This could be dated back to the time when the world was ruled under the sovereignty of hegemonic heterosexuality. Love between people of the same sex was afflicted and repressed because of the established law of prohibition by the authority, mostly equivalent to Phallus. Though silenced and castigated, homosexuality still maintained its transgressive aesthetic to challenge the hegemony in order to earn its legitimacy. Michel Foucault noted "[m]odern society is perverse"[Foucault, The History, 47]. Homosexuality, another form of human aphrodisiac desire and considered an transgressive perversion, ruptures the existence of unification and builds up the world with miscellaneous discourses. This implies that whether heterosexual or homosexual, human sexual desire or concupiscence cannot be simply wiped out by univocal discourse. Alienation and exclusion executed by the authorial voice cannot deny the fact of the existence of an underprivileged discourse. Thus, homosexuality should not become extinct even if confronting oscillation through human history.

Since homosexuality is not a new term to the public, its history should be given a thorough review. Given the identification and authenticity of the relationship between members of the same sex, homosexuality has existed and been documented in both Western and Chinese literature. In ancient Greece, the aesthetic of homosexuality was manifested by many philosophers, for example, Aristotle, Socrates, Plato and so on. In Nicomachean Ethics by Aristotle, he depicted that "[l]ove and friendship therefore are found most and in their best form between such men" [130]. This idea implies that sexual orientation was not a disputable 
issue by ancient Greeks, and that identity of homosexuality went beyond the censorship of modern Western standards. Sexual desire and behavior should not be limited to the gender of the participants. Male relationship could be both friendship and love unconditionally. Accordingly, Aristotle confirmed the essence and the legitimacy of male relationships. Meanwhile, The Iliad by Homer firstly recorded love between two men, Achilles and Patroclus. The Trojan War began because Achilles could not endure the pain caused by the death of his friend/ love, Patroclus. Achilles admitted that "[b]ut how can I rejoice? My friend is dead./ Patroclus, my dearest friend of all. I loved him" [Homer 160. 84-85]. Achilles depicted his sorrow and regret after knowing Patroclus had been killed by Hector. Then, he decided to take revenge: "I will no longer live among men if I do not make Hector pay with his death for Patroclus dead" [Hamilton 197]. In spite of a warning from his own mother of his imminent death, Achilles still determined to go to the war for his beloved Patroclus. These two examples exemplify that homosexuality has been recorded in the human history and its sublimity was appreciated with regard to its idiosyncrasy.

Compared to the modern Chinese culture, the ancient Chinese culture was not so prejudiced but tended to embrace male relationships. Even if homosexuality was not highly praised in ancient China, many literary works recorded homosexual behaviors in royal palaces throughout numerous dynasties. A number of emperors were speculated to have had homosexual relationships with beautiful men. In one Chinese historical document, Yi Zhou Shu, or the Book of Zhou, the relationship between emperors and men were recorded. It used the term "mei nan po lao" to imply such relationships. "Mei nan" means beautiful men and "po lao" means breaking the wisdom from the old in Chinese. The phrase literally implies that emperors were constantly attracted by beautiful men so that words or wisdom from the elderly were consequently ignored. Another significant example happened to emperor Han Aidi. History of Western Han, or Han Shu documented "Duan xiu zhi pi," or "cut sleeve" to describe the emperor's affection for a man. The emperor fell for a man, Dong Xian, who seldom went back home because of his detention by the emperor. Thus, the emperor made an exception to invite Dong's wife, a civilian, to live with them in the palace. Besides that, one day, still in bed with Dong, the emperor needed to attend a court meeting. In order not to awaken Dong, who slept with his head on the emperor's long robe sleeve, the emperor used a knife to cut off the lower half of his sleeve without hesitation. Similar to ancient Greek history, homosexuality was not considered a taboo in ancient Chinese dynasties. The transformation of homosexuality from being acknowledged to being prohibited as well as being denied its legitimacy becomes paradoxical.

The concept of a more conservative Chinese society holding repugnance for homosexuality is stigmatized. As mentioned above, in Chinese history, people tended to embrace homosexual conducts more than they do in modern times. The reason could be concluded that people's acceptance of homosexuality went inward after the westernization at the end of Qing Dynasty. Under the influence of Christianity, people became more conservative regarding sexual issues. The United States is a country founded by Puritans, who followed more strict discipline. They echoed family values in believing that a family consisted of a husband and a wife. Thus, marriage is sanctioned because of a man and a woman's procreation ability. Homosexuality, of course, was excluded from their beliefs. Later, in the Victorian era, sexuality was repressed, and society eschewed any deployment of sexuality. Oscar Wilde was imprisoned because he was a homosexual in terms of both his behavior and his works. In all, compared to the western world, even if it is not arbitrarily the truth, the misunderstanding of a closed attitude toward homosexuality in Chinese culture should deserve a thorough censorship. 
Besides religious reasons, being a homosexual and coming out of the closet are two major issues hovering over most Chinese families. In fact, people in Chinese culture do not become agitated to know whether a person is gay or not. What concerns them the most is if they can prolong their family lineage. This concept completely corresponds to the Puritan doctrine of valuing the core of a family. In other words, people do not deny the presence of homosexuality, but they have questioned the homosexual procreation ability in Chinese culture since the westernization. Even so, this kind of "objection" to homosexuality seems much milder compared to that of Christianity or Islam, which both consider it a crime. Gradually, homosexuality has been misplaced as a deviation from the dominant culture. In addition, homosexuality has suffered dissidence from the religious influence and has been misunderstood by the public. Jonathan Dollimore argues that any forms of sex "have no natural or biological reality. They are all idealogical constructs, effects of an oppressive discourse of heterosexuality" [58-59]. Dollimore implies that people project what they consider to be important when it comes to the issue of sex, and social order is formed on such a twisted value. Apparently, homosexuality has been attached with ideological mystification that internalizes its formation and popularity. The dominant heterosexual society, then, refers to homosexuality as a social stigma. Sexuality, actually, has no fixed figure, but, instead, is merely constructed by ideology. In this way, any forms of sexuality should be viewed as a discourse that features its idiosyncrasy. Because of this idiosyncrasy, homosexuality becomes a transgression against social convention, religious morality and family value.

Although homosexuality is not thoroughly recognized and accepted, human desire cannot be oppressed or silenced. The more the conventional force denies the existence of homosexuality, the more homosexuals turn to rebel and upset the order of law because "[s]ex was not something one simply judged; it was a thing one administered" [Foucault, The History 24]. This suggests that no one has the right to set a limitation on certain sex, or subjectively to undermine it. Everyone, instead, should deserves the right to define his or her own identity. In this regard, homosexuality, without a doubt, is deployed as an indiscretion alienated and discriminated against as a repugnant demeanor. Heterosexuality should not enjoy the privilege as the ultimate established law as well as the orthodox discourse. Judith Butler stated that "the body appears as a passive medium on which cultural meanings are inscribed or as the instrument through which an appropriate and interpretive will determines a cultural meaning for itself" [12]. She believes that sexuality is misinterpreted, as is homosexuality. Butler emphasized that sex and gender should not be arbitrary terms, not to mention the representation of homosexuality by a homophobic society. Butler further explained that "sex does not cause gender, and gender cannot be understood to reflect or express sex" [142]. This shows that homosexuality is not as unpresentable as it appears, but political and conventional interpretations marginalize the aesthetic of homosexuality. Therefore, homosexuality is not a lack, or should not be considered an Other. Everyone, as an individual, can choose to love regardless of the boundary of sex, or even a man-made law. The true essence of the individual lies in the attitude of how open he or she is toward his or her inner voice. The discourse of one's inner self and desires determines the completeness of one man. Claiming his or her own right to love is a representation of freedom. With such freedom, homosexuality appears as a deliberate transgression to condemn prohibition imposed on it. Love exists in many forms, and homosexuality is one of them. People are always attracted to love stories. Thus, love should not become a privilege merely exploited by heterosexuality.

Even though influenced by Western culture, Chinese culture has a more open-minded attitude toward homosexuality. Slash fiction, or Boys' Love (BL), is a genre that describes love between two beautiful young men. Despite the fact that some people might disagree with the features the BL fiction shares with homosexuality, both genres depict homoerotic desires. Foucault 
argued that "[h]omosexuality appeared as one of the forms of sexuality when it was transposed from the practice of sodomy onto a kind of interior androgyny" [The History 43]. His statement can be viewed as a description of how two men decide their roles in terms of love. Meanwhile, another critic commented that " $[t]$ he identification of female readers with a boy character is made possible because of the androgynous nature of bishonen" [Sihombing 152]. Here, "bishonen" means beautiful men, and even if the idea refers to the bonding female readers create while they read BL, it also indicates the androgynous features embedded in the love between two men. Like heterosexual love consisting of a man (doer) and a woman (receiver), homosexual relationships, though resulting in the same sex, can be affirmed with the roles of top and bottom, doer and receiver, too. Therefore, BL fiction cannot only be considered a subgenre, but should also be viewed as one part of homosexuality with regard to their shared similarities.

This genre originated from Japanese manga in the 1970s to fulfill the fantasy of Fujoshi ${ }^{1}$ (rotten women ${ }^{2}$ ). The narrative strategy of using boy-boy love to present rotten women's inner desire is to help build a fantastical space that has been removed by a patrilineal world. Lacking proper comfort and denied under heterosexual and phallic convention, these women's sexual desire is repressed in terms of phallic discourse and power. Only through reading such manga can they liberate their confined desire. Normally, in BL, the romantic narrative depicting homoerotic love between male protagonists can bypass female stereotypes so as to create a freedom of imagination for women who fail to obtain it in heterosexual erotica. Now, not only manga but also fiction adopts boy-boy love as its storyline to win more appreciation from readers and to justify the legitimacy to homosexuality. The reason why BL fiction has become so popular among those rotten women is its storyline. The world built in BL "constituted an escape from reality and at the same time provided a space for critical reflection on gender and cultural norms" [Suter 546]. BL fiction offers a platform for women to freely express their inner voice and repressed sexual desire. Reading BL fiction is a subversive act to challenge the patriarchal society and it also leads to the representation of women's liberation. Foucault once said that "[s] exuality is something that one has within oneself, a kind of dynamic, a movement, a perpetual impulse that is oriented toward a primary pleasure" [The Gay 391]. Since sexuality is an innate desire, no one has the right to deprive another person of it. In other words, one is born to enjoy the pleasure derived from yarning for sex. Here, sex objects should not merely be limited to biological given sex; instead, they could be any forms that accelerate the adrenaline to arouse sexual impulse. Therefore, boy-boy love, a reserve discourse, in BL fiction manifests the male intimacy outside the heteropatriarchal world.

Like homosexuality, BL fiction transcends concerns about gender guarded by convention. Butler argued that "to be a homosexual is to contest the compulsory syntax and semantics that construct 'the real'" [163]. Meanwhile, Andrea Wood agreed that boy-boy love in BL is not merely "queer because [it] depict[s] homoerotic love stories between men, but rather because [it] ultimately reject[s] any kind of monolithic understanding of gendered or sexual identity" [397)]. Obviously, both homosexuality and BL fiction aim at overthrowing patriarchal law with regard to love. Butler's "syntax" and "semantics" represent the law used to oppress disparaged sexuality, which is homosexuality; meanwhile, Wood refers to "monolithic understanding" as

\footnotetext{
${ }^{1}$ Fujoshi is written 腐女子 in Japanese. This is not a standard word but literally means "rotten" (fu 腐) and "girl(s)" (joshi 女子) and sounds like 婦女子, a standard word meaning “ladies” (Galbraith 2011).

${ }^{2}$ Fujoshi are rotten because they are enthusiastic about yaoi, a genre of of fan-produced fiction and art, usually manga, that places established male characters from commercial anime, manga, and video games into unintended romantic relationships, roughly analogous to "slash" fiction outside Japan (Jenkins 1992; Pagliassotti 2010).
} 
conventional ideology restraining homosexuality from manifesting its authenticity. Both critics acknowledge that a patriarchal world is not equivalent to Law, nor can it represent Law. The essence of law has been manipulated to marginalize the same-sex relationship owing to the anxiety menacing all social systems. In a heterosexual domain, homosexuality, considered the Other, bears the negative elaboration causing confusion in society. However, the existence of homosexuality constitutes sexual identity that "throws off the shackles of political correctness and explores the complexities of sexual attraction" [Cossman, 850]. It challenges the validity of phallic cultural convention that generates power and prohibition. Love should not become a mere privilege to the relationship between a man and a woman. Instead, love derived from two men or two women shapes the identity of homosexuals as well as manifests the existence of true love between members of the same sex. Accordingly, the same-sex relationship in BL fiction indicates a narrative strategy free from the social conventions and gender norm by constructing a fantastical world, where not only Fujoshi (rotten women) find liberation in reading boy-boy love but also homosexuality earns its self-affirmation.

Sharing the same idiosyncrasy featured by homosexuality, BL fiction, or slash fiction, intends to describe more of the formation of relationships between two men whereas homosexuality mainly focuses on how this relationship affects society. BL fiction emphasizes transgressive intimacy created between two straight men. Initially, two male characters do not identify themselves as gay, but just fall in love with each other, where the other happens to be of the same sex. Interestingly, "the relationship is called a character 'coupling"' and "[e]very character in a coupling is identified as either a top (seme) or a bottom (uke)" [Galbraith 221]. In reality, this relationship in BL fiction shares a similarity with homosexual relationships. In a queer world, a top and a bottom are used to describe the roles of each figure. For example, in Addicted, readers can easily tell which role each character plays. Bai Luo Yin, or Yin $\mathrm{Zi}$, is depicted as a female role in this novel. Living with his father, Yin Zi takes over the mother's role in his family. Although his father takes care of the family, "[i]f he could have made the house clean and neat, the house would not be a mess" [Chai Vol 14 ]. Most of the time, it is Yin Zi who plays the mother role of taking care of his father and the family. Affected by his parents' divorce, Yin Zi learns to be not only a son but also a mother of a family. His androgynous nature is "an embodiment of both male and female features" [Sihombing 151]. Unlike other men, Yin $\mathrm{Zi}$ develops an autonomous self that makes him an independent man as expected by society, while, at the same time transgressing the social rules to embody a female image to fill the void in his family. Due to Yin Zi's idiosyncrasy, Gu Hai, depicted as a top, or seme, is infatuated with Yin Zi.

Like Yin Zi, Gu Hai was born into a family where his mother dies when he is little and where his father, a lieutenant, is going to marry another woman, who happens to be Yin Zi's mother. Without love from his mother, Gu Hai does not maintain a good relationship with his father. In regard to his father's career and Gu Hai's sturdy personality, love in this family never exists, not to mention the gossip that Gu Hai's mother died because of his own father. His misunderstanding and hatred of his father deepens after his father decides to marry another woman. Before meeting Yin Zi, Gu Hai has never been loved. The role of mother is missing from his family. Even though he was born into a rich military family, Gu Hai does not know love or how to love until Yin Zi shows up in his world. One afternoon after school, Gu Hai follows Yin Zi back home. Seeing Yin Zi helping his father, at that moment, Gu Hai "felt so touched after seeing the father and the son were arguing who should lift the heaviest end of the table. Perhaps, life should be like the scene he saw in Bai's family. A dinner feast cannot compete with the everyday trivia that helped maintain family relationship" [Chai Vol 1 84]. His inner voice represents how much he wants to be loved and cared for. Even if he is supported financially by his father, his life could not compete with Yin Zi's simple but happy life. Another incident that 
attracts Gu Hai to show his interest in Yin Zi happens when Yin Zi tries to check out his name. Unlike other classmates, Yin Zi shows no fears when facing Gu Hai: "[r]egardless of the flaming stare from Gu Hai, Bai Luo Yin acts like nothing happens and examines book after book on $\mathrm{Gu}$ Hai's desk to check his first name" [Chai Vol 1 28]. In Gu Hai's life, almost everyone shows a certain degree of respect, or fear, of him because of his lieutenant father. Few people dare get close to Gu Hai; however, Yin Zi completely breaks through the wall built under the sovereignty of $\mathrm{Gu}$ Hai's family name. Chiang depicted that the "BL narrative may embody certain characteristics of resistance" [224]. Yin Zi, as a figure free of social boundaries, undoubtedly transgresses a hierarchal order embedded in $\mathrm{Gu}$ Hai's family name. The legitimacy of heteronormativity suffers subversion through Yin Zi's idiosyncrasy to Gu Hai.

As mentioned earlier, Yin Zi represents bottom, "uke," in this boy-boy love with Gu Hai. Their encounter can be dated back to the time when $\mathrm{Gu}$ Hai transfers to Yin Zi's class. Gu Hai is attracted to Yin Zi as soon as "Gu Hai looks at Bai Luo Yin's face for the first time. Though Bai is not so-called a handsome man, he has his own unique feature" [Chai Vol 1 29]. His first impression of Yin $\mathrm{Zi}$ does not explicitly depict a homosexual tendency but simply his admiration for a unique individual who happens to be a man. No doubt, Yin Zi is some kind of "beauty" that gradually leads Gu Hai to indulge in homosexuality as they spend most of the time together. Gu Hai's love for Yin Zi blossoms after seeing his handwriting, neat and clean.

BAI. Why did you tear my composition off my notebook? Why did you not tell me? How dare you?

GU. I admired your handwriting and you should have been happy. [Chai Vol 1 48]

Not only does handwriting represent a man's character but also how a man writes reflects his personality and personal traits. Gu Hai admits that "[h]e likes the handwriting so much. It is neither regular script nor semi-cursive script. The handwriting is completely owned by Bai Luo Yin" [Chai Vol 1 38]. In fact, tearing out one page full of Yin Zi's handwriting from his notebook denotes Gu Hai's desire to own him. Gu Hai is attracted not only to the beautiful words written by Yin Zi but also to the beauty of Yin Zi himself. The misconduct of tearing out the page could be considered a transgression of the social order. Furthermore, using this page under a blank paper to practice handwriting implies the physical touch that is about to happen between these two high school boys. Welker once commented that 'desire is a major focus of boys' love narrative" [855]. As mentioned earlier, handwriting represents a person's character as well as the person himself. This move conveys the significance of carnal desire precipitated by Gu Hai. To put it simply, love between these two young men is about to blossom.

Born into a military family, Gu Hai is depicted as a masculine overbearing man: "Gu Hai is truly the descendant of a solider with his sturdy height. Walking around the house, he incarnates the macho man character" [Chai Vol 1 8]. In the novel, Gu Hai receives military trainings on his father's military base every year. Though using the training as a way to ease his hatred for his father, Gu Hai unintentionally develops his body shape. With his strong and muscular body, in his PE class, he even defeats his teacher, a recently retired solider, in a pull-up-bar competition. Then, he becomes a fierce man whom male students are afraid of and female students adore. Obviously, Gu Hai's role can correspond to the description of a "seme" in the circle of the BL franchise. He is a metaphorical representation of the masculine image, who transcends concerns about gender issues. His vulnerability regarding Yin Zi not only forces him to "live outside the heteropatriarchal world" but also to strengthen his masculinity to protect his love [Welker 842]. One of the features depicted in "seme," other than masculinity, is his sexual desire that will lead him to "insert his penis and the uke character uses his anus to attain sexual pleasure" [Sihombing 150]. When Yin Zi's ex-girlfriend strategically plans to get back with Yin 
$\mathrm{Zi}$ again, $\mathrm{Gu}$ Hai could not help but rape him to secure and claim the territory. He tells Yin $\mathrm{Zi}$ that he cannot watch this vicious girl ruin his life again. Not only does Gu Hai exert his masculinity, but he also exposes transgressive intimacy that rebels against the patriarchy. Thus, raping Yin $\mathrm{Zi}$ becomes a way to strengthen the bonding generated from their repressed desire.

Raping in Addicted denotes its significance beyond its literal meaning. Once, performing sodomy was violently condemned as a form of profanation against not only religion but also social morality. As sexuality gradually manifests itself, sexual minorities are deployed in modern society. The issue of sex is no longer confined in the cage of moral values; however, the revelation of repressed love finds its outlet. One's inner self and desires represent the truth of individuals and "sexuality is regarded as the secret essence of the individual" [McNay 96]. Sexual impulse derived from Gu Hai's desire expresses a new interpretation of masculinity. "Ripping off his pants and ripping off his underwear" symbolizes getting rid of the social conventions imposed on homosexuality [Chai Vol 2 244]. Inserting his penis into Yin Zi's anus demonstrates the subversion as a way to rewrite the discipline outside the hierarchical restrictions. Yin Zi's ex-girlfriend stands for heteronormativity that predominantly constitutes sexual identities. After seeing Yin Zi being raped, she "keeps shaking. Even though she experienced many other frightening scenes, none of them surpasses the horror of witnessing her ex-boyfriend being raped ... the scene lain in front of her is a mental torture and it also paralyzes her judgement" [Chai Vol 2 245]. The reaction implies that a decisive mudslide is happening to affect conventional understanding of sexuality. Yin Zi's ex-girlfriend has been confined in the long-established doctrine that preaches love between a man and a woman. The doctrine teaches people that same-sex love is the source of evil, and that homosexuality, considered perverted Other, means deviant and unnatural behavior in need of control. She, of course, feels startled because what nurtures her and what she believes face a crisis. The rape scene breaks the web delicately knit by heterosexist expectations as well as confirming the love between these two young men. Orbaugh argued that "rape is always motivated by the aggressor's extreme love and desire for the victim and the victim eventually comes to accept and reciprocate the aggressor's love" [181]. A world with normality undergoes a drastic makeover. Love generating from these two young men not only transforms homosocial bonds into a homosexual relationship but also produces a homoerotic motif. In this novel, rape does not cause hatred or alienation; rather, it prologues the beginning of boy love.

One of the features of slash fiction, or BL, has is the love story between two male characters. Love between $\mathrm{Gu}$ Hai and Yin $\mathrm{Zi}$ is definitely not a contingency because their homoerotic relationship conveys paramount significance. As mentioned earlier, slash fiction is created as a way for rotten women (fujoshi) to escape reality. In reality, these women feel confined in the light of social convention; that is to say, their desire is repressed under the patriarchal hegemony. For them, enjoying love scenarios between two men and finding comfort after these two men have a happily-ever-after ending fill the void rotten women suffer in reality in terms of heterosexual love. Queer scenes in slash fiction not only "increase[s] its subversion through erotic depiction of nominally heterosexual main characters" but also empower rotten women to look for mental compensation "outside their hierarchal restrictions of mainstream, patriarchal society" [Booth 400]. As a way to alienate themselves from reality, rotten women consider their fantasy digression. Some people might ask: As there are plenty of other ways to express their repressed desire, why do they only find interest in boy-boy love? A patriarchal society is built on heterosexual relationships and "female-male or even female-female couples are too close to reality" [Galbraith 213]. Transgressive intimacy, like boy-boy love, creates fantasy that temporarily offers them a platform to break free from social convention. Moreover, such a relationship, violating heteronormativity, represents the silenced discourse, 
like rotten women themselves, who deserve to coexist with reality as an alternative. The love story between Gu Hai and Yin Zi indicates a fearless homosexual relationship built by two high school boys who defy the establishment of normality guarded by the heterosexual world.

In addition to ripping out one page of Yin Zi's notebook to mimic his handwriting, the love scenes between Gu Hai and Yin Zi can be located in different phases of their school life. Since mimicking handwriting by putting Yin Zi's paper at the "bottom," Gu Hai's intention to bond with Yin Zi begins by him moving a bit closer geographically, or physically, in class. Without Yin Zi's consensus, Gu Hai lies to the teacher by confirming "[w]e are good friends and sitting behind Bai (Yin Zi) encourages me to study harder" [Chai Vol 1 50]. Unaware of Gu Hai's motive, the teacher indirectly approves of Gu Hai's behavior to love Yin Zi. Moving behind Yin $\mathrm{Zi}$ in the classroom denotes physical touch in respect of sexual intercourse. While the handwriting paper has Yin Zi become a bottom, Gu Hai's sitting behind him conveys the idea of love-making from "behind," that is, Yin Zi's "behind." Not only do readers see the implication of sexual intimacy progressing, but they also perceive the emergence of deviant discourse carried out by this boy love against traditional social convention. In this relationship, literally, Gu Hai always leads in strengthening the bonding with Yin $\mathrm{Zi}$, not to mention proactively acknowledging his own confirmation of falling in love with him. More intriguing, the story does not end here. Thinking of more moves to attract Yin Zi's attention, Gu Hai cuts holes on his uniform. Sabotaging the completeness of the uniform denotes the defiance of the established Law. The uniform stands for rules and conformity, which appeal to a repressive and conventional world. Since Gu Hai "takes out a pair of scissors to cut holes on Yin Zi's uniform when he is taking a nap," he has determined to depart from predominantly heterosexist expectations. [Chai Vol 1 53]. Gu Hai's long-term abrogation of self-control that complies with the heterosexual desire symbolizes his dissatisfaction with the privileged heterosexuality paradigm. In addition, as sexual scenes are quite an important element in BL, cutting holes in his uniform can also suggest Gu Hai's phallic penetration into Yin Zi's body. Later in the novel, $\mathrm{Gu}$ Hai claims his jouissance after he "wears Bai's uniform with many holes on it and stands at the staircase thinking of what just happened. Regardless of Bai's bad temper, Gu Hai enjoys the smell from Bai's uniform" [Chai Vol 1 113]. Wearing Yin Zi's uniform indicates the accomplishment of Gu Hai's carnal desire; his libido breaks free of social constraints through physical intimacy with Yin Zi. Like a victor, Gu Hai celebrates his own unexpected success by forging his own interpretation of discursive legitimacy. Therefore, Gu Hai's own testimony of "enjoying the smell of Bai's uniform" reassures readers that this romantic relationship will blossom as a non-heterosexual discourse.

Another love scene happens when Gu Hai accidentally drugs Yin Zi. Putting two sleeping pills in Yin Zi's thermal bottle, Gu Hai manages to let him sleep in class as a prank; of course, this is also another way to draw Yin Zi's attention. However, Gu Hai is not aware that Yin Zi had taken medication for flu before drinking water from his own thermal bottle. This causes Yin Zi to fall into a very deep sleep as well as putting him in danger from the effect of taking different medications at the same time. After knowing that his joke may jeopardize Yin Zi's life, Gu Hai feels regret and starts to worry. Carrying Yin Zi on his back and rushing to the health center on campus, Gu Hai reveals his concerns for Yin Zi, not only as redemption for his misconduct but also as his determination to love him. One of their classmates claims that

In other people's eyes, the relationship between Gu Hai and Bai Luo Yin is like water and fire. However, Yo Qi believes that Gu Hai likes Bai Luo Yin a lot. Gu Hai never says hello to anyone, but he proactively does pranks on Bai Luo Yin more often than not. Gu Hai is cold and unfriendly to other people, but he is extremely passionate to Bai Luo Yin. Gu Hai tries every possible way to irritate Bai Luo Yin, 
but when he sees Bai in trouble, he is the first to jump in to help. [Chai

Vol 1 102]

Here, the school represents an institute used to confine people with its rules and regulations. The reality principle, like social convention and morality, is implanted in each individual confined in the space of school to forgo the privilege to love whoever one wants to love. Gu Hai, however, resists the domination of ideology inculcated into sexual minorities, like same-sex relationships. Revealing his love to Yin Zi regardless of the profanation against heterosexual law implies $\mathrm{Gu}$ Hai's conviction to constitute his own sexual identity. Catherine Crabtree suggested that "sexuality is conceived as a fundamental aspect of our inter-relatedness and desire to be with others," which means a man's sexuality cannot be merely defined by his biological sex, but the erotic drive to love someone without constraints constructs personal empowerment [250]. Gu Hai denies the paradox of fixed and unchangeable interpretation of sex that has dominated the heterosexual world. Significantly, his love and care for Yin $\mathrm{Zi}$ denotes his departure from heterosexist expectations.

The love between these two high school boys does not stop here. Another incident shows Gu Hai's protection of Yin Zi as a macho man. There is a boy, called Wu Fang, in the same school who is hostile to Yin Zi. As the son of a government official, Wu Fang feels agitated because "girls he is after always have crushes on Bai" [Chai Vol 1 108]. In addition, he does not understand why girls like Yin $\mathrm{Zi}$, born poor, rather than accept him, rich with higher social status. Therefore, his revulsion derives from his inferiority competing with Yin $\mathrm{Zi}$ in their interpersonal relationship. In order to retrieve his superiority, Wu Fang manages to insult Yin $\mathrm{Zi}$ in public, so he goes to Yin Zi's class to make a scene. He tells other students in class that "Bai Lou Yin is born without mother's love, and do you know what his mother actually do for loving? The truth may shock you ... a whore" [Chai Vol 1 108]. As soon as Wu Fang calls Yin Zi "a bastard," Gu Hai spares no energy by punching him many times in the face. At this moment, "Wu Fang is badly beaten by Gu Hai. His face is no longer recognized and his chin is dislocated. As Gu Hai gives two more punches on his face, four of his teeth fly out from mouth" [Chai Vol 1 109]. The riot here signifies the conflict between two major discourses, homosexual and heterosexual. As mentioned earlier, Wu Fang is from a family of a government official, which literally represents the order and law in society. Of course, it cannot tolerate any unexpected resistance generating from transgressive discourse. In Wu Fang's perspective, Yin Zi comes from the very bottom of society in terms of social stratification. As far as Wu Fang is concerned, people like Yin Zi should remain underprivileged as homosexuality should always hide in the dark, too. Nevertheless, independent of his own father, a military sergeant, Gu Hai eradicates the ideology embedded in a patrilineal world, which considers power a hegemonic law. Abandoning his identity inherited from his father, $\mathrm{Gu}$ Hai determines to create his own image and true self. By punching Wu Fang as a transgressive force, Gu Hai challenges heterosexual and phallic cultural conventions in terms of his homosexual desire to protect Yin $\mathrm{Zi}$.

While defying the established law and rejecting the internalized prohibition, Gu Hai elaborates his love and care for Yin $\mathrm{Zi}$ in the form of homoerotic romance. One of the love scenes manifests $\mathrm{Gu}$ Hai's determination to be a "seme," or a "top" when he confesses to Yin Zi. A "seme" and a "uke," mentioned earlier, are two important characters in BL fiction. Like a top and a bottom in the homosexual relationship, both Gu Hai and "Yin Zi follow the pattern of BL arrangement quite well. Besides raping Yin $\mathrm{Zi}$, as the story moves on, both of them enjoy sexual intercourse in the second volume of the novel after they are married. However, what makes their love so significant should be given a thorough inspection, and how it begins leaves an impact on affecting the heterosexual world. In the previous paragraph, Gu Hai accidentally drugs Yin Zi, which turns his own prank into concerns about Yin Zi. While taking care of Yin Zi 
in the health center on campus, Gu Hai's confession triggers a homoerotic motif. A conversation between Gu Hai and Yin Zi manifests a freedom of sexual exploration.

BAI. Jesus! Are you a psycho?

GU. Yes, I am.

BAI. If so, then take medication.

GU. You are my medication. [Chai Vol 1 105]

The conversation happens after Yin Zi wakes up from his drug poisoning. Yin Zi feels confused about why $\mathrm{Gu}$ Hai always picks on him even while ignoring him. He acknowledges that as a person from the bottom rungs of society, Gu Hai, born into a military family, would never be his friend, let alone could break the social boundary to love him. However, "You are my medication" symbolizes Gu Hai's commitment to protecting Yin Zi both physically and affectionately. Moreover, it also suggests that the current social status quo no longer sustains $\mathrm{Gu}$ Hai's belief, and the appearance of Yin Zi, as the alienated Other, in his life redeems his guilt of violating the social norms.

Further evidence of Gu Hai's love for Yin Zi is reflected in his motivation to buy breakfast. Noticing that Yin Zi never has a proper breakfast at home, Gu Hai decides to bring him breakfast. Not knowing what Yin Zi likes, Gu Hai buys all kinds of food, eastern and western style. Yin Zi feels shocked to to see

a huge bag with a lot of food after putting down his school bag. The

bag has everything he ever wants, including western pastry, like bread,

sandwiches, tarts, which he does not like, and eastern one, like sesame

pancakes with ham, meat buns, rice pancakes, and mixed congee,

which he likes. [Chai Vol 1 85]

A variety of food indicates Gu Hai's patience and perseverance to not only care about Yin Zi but also to fight against the conventional society. In fact, no one can obtain these foods Gu Hai buys for Yin Zi in one particular shop or store. Gu Hai needs to get up early to shop from door to door and bring them to Yin Zi's desk before he arrives. Despite sacrificing his own time and energy, Gu Hai still feels happy about that. From here, it can be concluded that Gu Hai's resolution to disclose his homoerotic love to Yin $\mathrm{Zi}$ depicts his antagonism towards heteronormativity. His intention to protect what he loves and what he believes transcends the social order that dominated his life before he met Yin Zi. By virtue of releasing his desire to own Yin $\mathrm{Zi}, \mathrm{Gu}$ Hai defines his own interpretation of the norms. The escape from the established phallic dogmas drives $\mathrm{Gu}$ Hai to demonstrate his love of Yin $\mathrm{Zi}$ as a form of narrative outlaw oppressed in the homophobic world. As a man free of social convention, $\mathrm{Gu}$ Hai never hides his true feelings and is eager to articulate them. One of his classmates even confirms Gu Hai's unconventional characteristic and says "I think Gu Hai likes you a lot. Anyway, whenever I turn around, I see Gu Hai is always looking at you" [Chai Vol 1 89]. Significantly, Gu Hai hopes that people could acknowledge his love for Yin Zi, and this love makes no difference from heterosexual love. Although the love object may not meet the heterosexual expectation, his non-heterosexual affection for Yin Zi should also exist as a form of power dynamics.

After the riot caused by Wu Fang, the relationship between Gu Hai and Yin Zi manifests itself. While Gu Hai proactively articulates his desire to construct a transcendental relationship, Yin $\mathrm{Zi}$, haunted by the threat of incorporation of perversions, neglects the power of confession made by a reverse discourse. Boy-boy love, considered a form of perversion, is excluded from social and economic operation, full of ideology against homosexuality. However, the fight against Wu Fang, an incarnation of phallic discourse, completely eliminates Yin Zi's fear of 
violating the established law, which Gu Hai has been dealing with. Not willing to see Gu Hai's uniform with the blood stain from hitting Wu Fang, Yin Zi "helps Gu Hai take off his uniform while he is taking off his and gives it to Gu Hai" [Chai Vol 1 113]. This explains that Yin Zi finally accepts $\mathrm{Gu}$ Hai's attention to him and hopes to stand on $\mathrm{Gu}$ Hai's side to fight against heteronormativity together. The exchange of uniforms, initiated by Yin Zi, not only implies a solid physical touch he returns as a favor to $\mathrm{Gu}$ Hai but also indicates their determination to escape their sexual inferiority. Yin Zi also uses his own way to protect whom he loves and what he believes just like the way Gu Hai does to him. As mentioned earlier, the uniform represents the power that dominates people, and here the uniform with blood stains illustrates the collapse of the established social order. Thus, helping Gu Hai to take off his uniform symbolizes their success over the Law, and the ideology propagandized by the Law allegedly undergoes a thorough scrutiny. Furthermore, the homoerotic relationship is further constructed when "Bai Luo Yin's arms hold around Gu Hai's shoulders and every breath flirts with Gu Hai. Gu Hai suddenly feels the heat staying on his own neck as Bai's face touches his neck more than once" [Chai Vol 1 118-19]. The physical touch corresponds to transgressive intimacy that BL fiction adopts as a measure to demonstrate a dispersion of sexualities. Boy-boy love, or homosexuality, reveals oppressed homoerotic desire in order to retrieve sexual identity. Foucault once argued that "our epoch has initiated sexual heterogeneities," which implies that an unorthodox discourse has risen to revolt against the legitimacy of the established law [The History 37]. When Yin Zi consents to Gu Hai's revelation of homosexual intimacy to him, the power struggle between homosexual and heterosexual discourse has begun.

The topic of sexuality has been problematic and controversial, especially when it comes to homosexuality. The idiosyncrasy of sexuality has been overused by certain groups of people by virtue of a power struggle. The power dynamic should not become an arbitrary privilege enjoyed by only a few people. Butler argued that "sexuality is always constructed within the terms of discourse and power, where power is partially understood in terms of heterosexual and phallic cultural conventions" [40]. Butler pointed out that while power is exploited by certain discourses to create prohibition, oppressed and alienated sexual minorities deny the political and economical deployment in the light of social equilibrium. With the romantic narratives inscribed in BL fiction, boy-boy love depicts homoerotic affection between male protagonists to reject the estrangement from confined imagination, like $\mathrm{Gu}$ Hai and Yin $\mathrm{Zi}$ in Addicted. Both Gu Hai and Yin Zi construct significance of fantasy by overcoming their fear and embracing their love, regardless of the prohibition from social conventions. Not until Yin $\mathrm{Zi}$ confesses "there is a special someone I like" to reject his ex-girlfriend is a new interpretation of masculinity derived through queer reading [Chai Vol 2 171]. In Addicted, it is not hard to notice these protagonists show their homoerotic feeling without constraints. Even though Yin $\mathrm{Zi}$ undergoes a certain degree of turbulence in this love relationship, they both, to a certain degree, acknowledge and confess to each other. Confession provides them with the power to relocate their identities. Foucault commented that "confession produces intrinsic modifications in the person who articulates it ... it unburdens him of his wrong, liberates him" [The History 62]. Confession apparently frees and produces truth, so truth coexists with freedom and with the one who respects the value of it. Each of their confessions concerning oppressed homosexuality insinuates a symbol of sex liberation. They intend to construct a fantasy world free from homophobia, using same-sex love as an independent discourse, not an antithesis of heterosexuality, to form reversible and adjustable identifications.

Although BL fiction place more emphasis on the escape of female readers from reality than the relationship of the male characters in the story, there is no denying that BL fiction does share similarities with homosexual interpretations by virtue of how protagonists interact with each other, both mentally and physically. Fran Marten confirmed that "given their narrative 
thematization of sexual and romantic relations between men, BL texts certainly do raise the topic of male homosexuality" [371]. Female readers adopt BL fiction as a way to reflect their inability to express their desire in a patriarchal society. Projecting their desires onto homosexual romances fills the void deprived from heterosexual ones. The romance between male protagonists can be read as a symbol of liberation, echoing the feminine passivity in a heterosexual relationship. As BL fiction allows women to freely articulate their sexuality, the impact of homoerotic romance narratives undoubtedly assaults the legitimacy of heteronormativity. The deployment of homosexuality, seen as a reverse discourse, should result in self-affirmation rather than an exclusion of sexuality. Catherine Salmon and Donald Symons argued that BL fiction "is in essence a love story in which two long-term male partners, usually depicted as heterosexual, suddenly realize that they have come to love one another" [97]. This indicates that sexuality does not predetermine any symbolic interpretation in any sex. In Addicted, Gu Hai and Yin Zi have girlfriends before they meet each other. As the story proceeds, it is exemplified that they are not born heterosexual, nor are they homosexual. The androgynous feature denies the misconception of univocal sexuality attached to both of them. In other words, everyone is capable of choosing whom they love regardless of sexual boundaries. Homosexuality and heterosexuality should not be considered two oppositions, but, in fact, they mutually define each other. A romance between two men defines the existence of heterosexuality as "a macho homophobic male [being able to] define himself as straight only in position to that which he is not- an effeminate gay man" [Namaste 222]. In BL fiction, the assertion of male same-sex intimacy articulates the dissatisfaction with traditional gender depiction, and homosexual relationships, to a certain degree, bypass misogyny and offer freedom of sexual exploration. Love between two men goes beyond the constraint imposed by social value and ideology. With all the similarities found in BL fiction and homosexual texts, a queer reading of BL fiction offers an innovative approach not only to challenge the conventional concept of boy-boy love but also to justify a non-heterosexual discourse.

\section{Works Cited}

Aristotle. Nicomachean Ethics. Trans W.D. Ross. Kitchener, Ontario: Batoche Books, 1999.

Booth, Paul. "Slash and Porn: Media Subversion, Hyperarticulation, and Parody." Continuum: Journal of Media \& Cultural Studies 28.3 (2014): 396-409.

Butler, Judith. Gender Trouble: Feminism and the Subversion of Identity. New York: Routledge, 1999.

Chiang, Feichi. “Counter public but Obedient: A Case of Taiwan's BL Fandom.” Intra-Asia Cultural Studies 17.2 (2016): 223-38.

Cossman, Brenda. "Sexuality, Queer Theory, and 'Feminism After' :Reading and Rereading the Sexual Subject." McGill Law Journal 49.4 (2004): 849-76.

Crabtree, Catherine. "Rethinking Sexual Identity.” Existential Analysis 20.2 (2009): 248-61.

Dollimore, Jonathan. Sexuality Dissidence: Augustine to Wild, Freud to Foucault. Oxford: Oxford UP, 1991.

Foucault, Michel. “The Gay Science.” Trans. Nicolae Morar and Daniel W. Smith. Critical Inquiry 37.3 (2011): $385-$ 403.

--. The History of Sexuality. Trans. Robert Hurley. New York: Vintage Books, 1990.

Galbraith, Partick W. “Fujoshi: Fantasy Play and Transgressive Intimacy among 'Rotten Girls' in Contemporary Japan." Sign 37.1 (2011): 219-40.

Hamilton, Edith. Mythology: Timeless Tales of Gods and Heroes. New York: Warner Books, 1999.

Homer. “The Iliad.” The Norton Anthology of Western Literature, Volume $18^{\text {th }}$ ed. NY: W.W. Norton and Co., 2006. Jenkins, Henry. Textual Poachers: Television Fans and Participatory Culture. London: Routledge, 1992.

Martein, Fran. “Girls who Love Boys' Love: Japanese Homoerotic Manga as Trans-national Taiwan Culture.” IntraAsia Cultural Studies 13.3 (2012): 365-93. 
McNay, Lois. Foucault: A Critical Introduction. Cambridge: Polity P, 1994.

Namaste, Ki. "The Politics of Inside/Out: Queer Theory, Poststructuralism, and a Sociological Approach to Sexuality." Sociological Theory 12.2 (1994): 220-31.

Orbaugh, Sharalyn. "Girls Reading Harry Potter, Girls Writing Desire: Amateur Manga and Shōjo Reading Practives." In Girl Reading Girl in Japan. Ed. Tomato Aoyama and Barbara Hartley. London: Routledge, 2010. 17486.

Pagliassotti, Dru. "Better than Romance? Japanese BL Manga and the Sub-genre of Male/Male Romantic Fiction." Boys Love Manga: Essays on the Sexual Ambiguity and Cross-Cultural Fandom of the Genre (2010): 59-83.

Salmon, Catherine, and Donald Symons. Warrior Lovers: Erotic Fiction, Evolution and Female Sexuality. New Heaven, CT: Yale UP, 2004.

Sihombing, Febriani. “On the Iconic Difference between Couple characters in Boys Love Manga." Image \& Narrative 12.1 (2011):150-65.

Suter, Rebecca. “Gender Bending and Exoticism in Japanese Girl’s Comics.” Asian Studies Review 37.4 (2013): $546-$ 58.

Welker, James. “Beautiful, Borrowed, and Bent: 'Boys Love’ as Girls Love in Shôjo Manga.” Sign 31.1 (2006):84170 .

Wood, Andrea. “'Straight' Women, Queer Texts: Boy-Love Manga and the Rise of a Global Counterpublic.” WSQ 34.1\&2 (2006): 394-414.

柴雞蛋 (Chai Jidan). 上㒣 Vol 1. 台北 : 時報文化, 2016.

柴雞蛋 (Chai Jidan). 上㶐 Vol 2. 台北：時報文化, 2016. 